\title{
Tornar-se cientista: o ponto de vista de Bruno Latour
}

\author{
Becoming a scientist: the perspective \\ of Bruno Latour
}

André de Faria Pereira Neto 1

1 Escola Nacional de Saúde Pública, Fundação Oswaldo Cruz.

Av. Brasil 4036, sala 401, Rio de Janeiro, RJ 21040-361, Brasil.
Abstract The purpose of this article is to raise some points for an understanding of contemporary French philosopher Bruno Latour's perspective on the professionalization process for scientists. We review part of the sociological literature that has attempted to conceptually differentiate occupations from professions. We thus intend to establish a number of comparative parame ters for such concepts. The field of knowledge and its role in the stages of the professionalization process assume an important place in this reflection.

Key words Profession in Science; Sociology of Science; History of Science; Philosophy

Resumo O objetivo deste artigo é introduzir al guns el ementos para a compreensão da vi são que o fil ósofo contemporâneo francês Bruno Latour tem a respeito do processo de profissi onalização do cientista. Para tanto, percorreremos parte da literatura sociológi ca que procurou diferenciar conceitualmente uma ocupação de uma profissão. Assim, pretendemos estabelecer alguns parâmetros comparativos entre essas duas concepções. O domínio do conheci mento e seu papel na etapa do processo de profissional ização assume, nesta refl exão, posi ção de destaque. Palavras-chave Profissão em Ciência; Sociologia da Ciência; História da Ciência; Filosofia 


\section{Introdução}

Como alguém se torna cientista? Ao longo do artigo "As profissões", publicado no livro "A Ciência em Ação" (1989), Bruno Latour pretende desmistificar a resposta que se tem comumente para esta pergunta. Para a boa parte da opinião pública, uma pessoa torna-se cientista quando usa jaleco branco e demonstra estar pouco interessada na política institucional de seu local de trabalho. Preocupar-se com isto não é coisa de cientista... afirmam alguns. Se o cientista procurar conseguir verbas para seu laboratório, não terá tempo para desenvolver a denominada pesquisa pura ... alertam outros. Estas ponderações, por vezes, são feitas, inclusive, nos corredores e nas reuniões de algumas instituições voltadas para produção de pesquisa básica no Brasil de hoje. No nosso entender, Latour, neste artigo, concentra seus esforços em tentar desfazer esta visão de ser cientista, tão enraizada no imaginário coletivo tanto no meio científico quanto na sociedade em geral.

Para tornar-se um cientista, a atividade no laboratório é suficiente? Quem passa todo o tempo procurando captar finaciamento ou reconhecimento para um projeto não pode ser considerado um cientista? Para responder estas questões, Latour (1989) faz outras interrogações de caráter mais abrangente, tais como: O que é uma profissão? Como diferenciá-la de uma ocupação? Como se caracteriza o processo de profissionalização?

O objetivo deste trabalho é apresentar, de forma sumária, como Bruno Latour respondeu a estas perguntas. Para mel hor compreender suas inquietações, sua visão será contraposta àquela enunciada por Wilensky (1970), quando define "profissão" e "processo de profissionalização", e a alguns postulados das vertentes internalista e da externalista de compreensão da natureza do trabalho do cientista.

Com isso, procuraremos desenvolver uma análise ao mesmo tempo crítica e epistemológica sobre o ser cientista. Consideramos esta reflexão de inegável relevância para o campo da Saúde Pública, onde atuam muitos cientistas, assim denominados formalmente e reconhecidos socialmente.

Além disso, pretendemos, mais uma vez, comprovar que o trabalho crítico com o conceito profissão, analisado do ponto de vista sociológico e histórico, é legítimo e imprescindível para todos aqueles que se interessem pela organização do trabalho na área da saúde.

O estudo de Latour, que analisaremos a seguir, é apenas um dos que tomou concretamente a profissão como objeto de pesquisa.
Seu grande mérito foi o de ter introduzido uma perspectiva de análise teórica e metodológica extremamente inovadora e crítica.

$\mathrm{Na}$ verdade, este artigo pretende tratar simultaneamente dois aspectos: ressal ta a relevância e a pertinência da abordagem sociológica e histórica sobre o objeto profissão e analisa como um autor contemporâneo francês - Bruno Latour - fez este tipo de empreendimento, comparando-o com outro, da mesma natureza, promovido pelo norte-americano Wilensky, vinte anos antes.

\section{O lugar do conhecimento: a primeira diferença}

Para ser cientista, basta dominar um determinado conhecimento?

Segundo o senso comum, qualquer atividade humana no mundo do trabalho é considerada uma atividade profissional. Nas sociedades complexas e pós-industriais, entretanto, as atividades do setor terciário - particularmente as que requerem uma formação de nível superior - aumentaram de número e de importância neste século. Assim, a crescente racionalização e intelectualização deste segmento da atividade produtiva promoveu sua hierarquização. O trabalho com a ciência é hoje organizado em “disciplinas especiais a serviço do auto-esclarecimento e conhecimento de fatos inter-relacionados. Não é um dom da graça de videntes, nem participa das contemplações dos sábios" (Weber,1982:130). Nas sociedades complexas e pós-industriais como aquelas em que vivemos, as atividades do setor terciário, particularmente as que requerem uma formação de nível superior, aumentaram de número e importância.

Wilensky foi um dos sociólogos das profissões que buscou, exatamente, analisar as especificidades das atividades de nível superior, procurando identificar entre elas uma hierarquia. Ele partiu desta premissa e seguiu, ainda, alguns dos postulados fundadores da sociologia de Durkheim (1984). “Na visão durkeimiana a sociedade moderna está caracterizada, basicamente, pela divisão do trabal ho através das diferentes profissões e especializações" (Machado, 1995b:13). Por esta razão, Wilensky procurou definir alguns elementos constitutivos de uma profissão. Seu intuito era, ainda, determinar algumas diferenças entre as ocupações e as profissões. Fixados estes atributos, buscou identificar também, por exemplo, algumas ocupações em vias de se profissionalizar e algumas profissões que tendiam à desprofissionalização. 
A preocupação central de Wilensky (1970) era estabelecer critérios suficientes que fossem capazes de distinguir a natureza do trabal ho do carpinteiro daquele exercido, por exemplo, por um médico. Neste sentido, o domínio do conhecimento era, para ele, um fator que adquiriu especial importância.

Para Wilensky, "qualquer profissão que deseje exercer sua autoridade profissional deve encontrar uma base técnica para isto, sustentada em exclusiva jurisdição, habilidade e leis ligadas ao treinamento padronizado, convencendo o público de que seus serviços são dignos de confiança. O conhecimento profissional, como todo o conhecimento, deve ser relativamente tácito, e é isto que dá às profissões estabelecidas sua aura de mistério. (...) O conhecimento pode ser deliberadamente usado como um meio tático, como um recurso para construir prestígio e poder. (...) A base do conhecimento ou doutrina para a profissão é uma combinação do conhecimento prático e intelectual, parte do qual é explícito (livros, leituras, demonstrações), parte implícito. Os aspectos teóricos do conhecimento profissional e os elementos tácitos do conhecimento intelectual e prático tornam necessário o treinamento longo que persuade o público do mistério da tarefa" (Wilensky, 1970:483-484).

Como acabamos de observar, Wilensky considera o domínio do conhecimento um elemento imprescindível para a reivindicação de exclusividade para a realização de determinada tarefa. Este conhecimento deve ser, no seu entender, extremamente complexo, organizado e sistematizado em Universidades e sociedades de saber. O profissional deve ter um vocabulário compreensível apenas por seus pares. Com estas características, nem todos teriam acesso a este tipo de conhecimento. $O$ domínio do conhecimento é esotérico, ou seja, ministrado a círculo restrito e fechado de ouvintes e compreensível apenas por poucos. Este é um ponto central na definição do que venha a ser uma profissão para Wilensky.

Marinho (1986) corrobora com esta concepção. Para ele é fundamental o papel que o domínio de um conhecimento especializado exerce na obtenção e na manutenção do status e sucesso profissional (definido em termos de conquista de um monopólio de competência). Segundo o autor, "as ocupações que possuem, em sua base cognitiva, um conhecimento paradigmaticamente orientado (isto é, formal e definido), tido como esotérico e suscetível de aplicação prática, encontram menores dificuldades na conquista de seu monopólio de competência e conseqüentemente do território profissional exclusivo" (Marinho, 1986:11).
Este mesmo elemento tido como essencial para Wilensky, e reiterado recentemente por Marinho (1986), recebe de Latour, no mesmo esforço conceitual, peso distinto. No seu entender, o monopólio do conhecimento, nas características apontadas anteriormente, não representa elemento nem suficiente nem determinante para a definição de uma profissão. Ele afirma: "Sem o recrutamento de numerosos aliados, sem a tática sutil que permite ajustar simetricamente os recursos humanos e não humanos, a retórica da ciência torna-se impotente" (Latour,1989:236). A questão do domínio do conhecimento, em si, para Latour, é menos importante que as estratégias que o corpo profissional desencadeia para convencer seus pares, a sociedade e o Estado de sua existência e utilidade.

Analisando especificamente a evolução das profissões da saúde nos dias de hoje, Machado (1991) considera que “as modificações histórico-sociais ocorridas na sociedade afetaram de maneira decisiva o campo de ação e a definição deste profissional". Ela complementa seu ponto de vista afirmando: “O conceito sociológico clássico que define a profissão médica monopólio de uma área específica de atividade, a partir de uma larga formação intelectual, adesão de todos os membros da profissão a um sistema de valores, autonomia de trabal ho entre outros - como uma profissão típica e nobre entre as profissões, está cada vez mais distante da situação atual" (Machado, 1991:32).

Concordando com Machado (1991) e sugerindo outros elementos que precisem ainda mais este debate, consideramos importante ressaltar duas questões:

Por um lado, a atividade profissional, objeto de investigação de Wilensky no final dos anos 60, difere muito da referência prática que serviu de base para as reflexões de Latour, em meados dos anos 80 . As condições históricas atuais impõem ao exercício das profissões elementos que não eram observados, de forma sistemática, há vinte anos atrás. Hoje em dia o trabalho social de cunho profissional carrega extensa e intensa tecnologia e confere, por exemplo, significativo papel ao domínio dos meios de comunicação e informação como meios de obter prestígio, reconhecimento e poder.

Por outro, cabe ressaltar que Wilensky vincula-se à escola durkheimiana norte-americana, que "apostava numa sociedade harmônica, capaz de gerir seus conflitos e conferia às corporações papel crucial no processo democrático" (Machado, 1995b:14). Latour inscreve-se na contemporânea corrente de sociologia das 
ciências que busca dirimir as oposições, ainda muito cristalizadas no meio acadêmico, entre a versão externalista e a internalista de lidar com a história da produção do conhecimento científico. Sua postura metodológica porta um tom intensamente interdisciplinar, utilizando-se, por vezes, por exemplo, da etnologia e da antropologia. Podemos, então, concluir que estes dois anal istas militam em distintas escolas de pensamento. Além disso, os trabalhos, que foram objeto de nossa investigação neste texto, foram produzidos em momentos históricos distantes e diferentes entre si, influenciados, portanto, por referências teóricas e problemáticas metodológicas que chegam a ser, em certo sentido, antagônicas.

No nosso entender, uma análise que procure identificar as diferenças existentes entre duas abordagens distintas sobre um mesmo conceito deve levar em consideração o momento histórico em que elas foram respectivamente elaboradas. Caso contrário, o analista corre o sério risco de não conseguir perceber seu significado mais profundo. Uma das práticas mais constantes entre cientistas sociais que anal isam o pensamento de certo autor é fazêlo sem levar em consi deração as condições sócio-econômicas, as escolas de pensamento e as inquietações filosóficas que informaram as idéias expostas por ele.

O processo de profissionalização: segunda diferença

Partindo dos pressupostos introduzidos anteriormente, passemos agora a acompanhar como os dois autores concebem o processo pelo qual as atividades do mundo do trabalho, sobretudo aquelas que requerem uma formação especializada em escolas criadas para este fim, podem se transformar, até atingirem o status profissional.

Wilensky parte de uma pesquisa desenvolvida junto a 18 atividades profissionais desempenhadas nos Estados Unidos e estabelece os "cinco passos do processo de profissionalização", a saber:

1) A ocupação deve ser exercida em regime de tempo integral. Para que isso ocorra, é necessário que haja, por um lado, a demanda pelo serviço e que este seja aplicável a situações concretas. Com isso, ficam excluídas desta categoria as atividades feitas esporadicamente.

2) O domínio do conhecimento esotérico fica assegurado se forem criadas escolas de treinamento onde ele é exclusivamente veiculado. Assim, ficam excluídas as atividades cujo co- nhecimento é transmitido de forma hereditária, informal ou com base na simples observação. A sistematização e universalização do conhecimento em instituições é a garantia do monopólio exercido pelo profissional. No seu entender "o treinamento padronizado é requisito para integrar uma profissão" (Wilensky, 1970:489).

3) A seguir, devem ser constituídas as associações profissionais, voltadas para defender seus interesses econômicos e construir uma padronização de conduta que deverá ser cumprida por todos os seus integrantes. Com isso, eles se sentirão parte de um corpo profissional portador de certa identidade. A associação profissional visa, assim, separar os competentes dos incompetentes; definir responsabilidades essenciais à profissão; regular o conflito interno não só entre os praticantes como entre estes e os atores externos. Em alguns casos a competição aguda com ocupações vizinhas e concorrentes pode ser observada. Se este for o caso, a associação profissional representará os interesses da corporação no sentido de garantir o monopólio do exercício daquela atividade. Elas caracterizam-se por não pleitearem exclusivamente melhorias nas condições de trabalho. A garantia da auto-regulação é elemento imprescindível para a conquista de prestígio, reconhecimento e poder da profissão junto a seus pares, a seus clientes e à sociedade em geral, pré-requisito para garantia do monopólio do território para o exercício profissional.

4) Para que esta região de competência fique claramente definida, é necessário, sobretudo, intensa atividade política no interior das diversas instâncias de poder público. Assim, a profissão organizada e atuante pode ser regulamentada, assegurando para si, oficialmente, o monopólio de competência. Portadora desta prerrogativa legal, a profissão terá os meios para inibir, coibir ou penalizar todo aquele que concorra com ela sem ter se submetido ao mesmo ritual ou cumprido as etapas que a profissão proclama como imprescindíveis para que alguém possa exercê-la plenamente.

5) A última etapa ocorre com o estabelecimento de um código de ética que garanta legalmente o direito de expurgar os profissionais que não se submetam às normas de conduta estabelecidas previamente entre os pares ou com clientes. Mais uma vez, é significativo o papel desempenhado pelos instrumentos de auto-regulação. Desta feita não se trata de convencer os pares e sim de fiscalizá-los e até puni-los por transgressões a um código de ética, coletivamente criado. Um profissional, desta 
forma, terá condições de julgar e punir o colega. Este julgamento tem valor legal e pode levar até ao impedimento do exercício da atividade.

Latour propõe, igualmente, cinco etapas no processo de profissionalização, a saber:

1) Em primeiro lugar, o profissional deve ser alguém capaz de eliminar os amadores e viver do trabal ho. No seu entender, o exercício profissional impõe uma dedicação exclusiva e integral à atividade. Caso contrário, ela pode ser abandonada a qualquer momento. O profissional difere do amador, pois sobrevive com o que ganha desempenhando sua atividade. Os amadores, entretanto, devem ser preservados como força de trabalho indispensável, submissa e disciplinada pelo profissional, que não deve perder tempo com suas opiniões.

2) A veiculação do conhecimento em revistas e museus e demais órgãos de divulgação científica levaria a profissão a atingir um público mais amplo. Com isso, aumentaria o número de pessoas interessadas em absorver seus princípios e utilizar seus serviços, sem que ele seja vulgarizado de forma panfletária. Para profissionalizar-se, uma atividade deve estabelecer estratégias para atrair o público e satisfazer a sociedade. Com isso, constituir-se-ia um mercado de consumo para seus serviços.

3) A profissão deve ser hábil e capaz de convencer e provar ao Estado que sua atividade é imprescindível para a sociedade. Ao mesmo tempo, sua autonomia deve ser garantida: todas as ingerências devem ser evitadas.

4) O profissional constitui-se quando se submete a um ritual rigidamente estabelecido pelo ensino universitário, que padroniza e impõe normas rígidas para a formação de jovens colegas.

5) Finalmente, a profissão deve ser capaz de definir normas de conduta entre os pares, que visem promover meios de resolver controvérsias internas, deixando os amadores do lado. A punição de um colega está prevista, pois objetiva, sobretudo, preservar a imagem e o prestígio do corpo profissional junto aos clientes, ao Estado e à sociedade em geral.

Comparando as duas abordagens configurar-se-á a seguinte tabela:
Analisando atentamente o quadro que se configurou, dificilmente alguém seria capaz de identificar divergências ou disparidades entre as abordagens de Wilensky e Latour. As convergências, aparentemente, predominariam, na medida em que quatro das cinco atividades previstas são comuns aos dois autores. A questão, entretanto, não é quantitativa, apesar desta dimensão não poder ser menosprezada.

No nosso entender, a questão central que diferencia o ponto de vista de Wilensky (1970) daquele introduzido por Latour (1989) é de natureza duplamente metodológica.

Por um lado, cabe ressaltar que, para o sociólogo norte-americano, as cinco etapas propostas comporiam uma progressão universal de acontecimentos: um caminho que todas as atividades deveriam cursar para conquistar o estatuto de profissão. Assim, para Wilensky, todas as ocupações que estivessem em vias de se profissionalizar deveriam atingir as etapas por ele enunciadas na ordem que foram descritas. Sua visão independe da natureza da atividade, do momento histórico ou da realidade social em que ela buscava se profissionalizar. Para Latour, estes cinco fatores integrantes do processo de profissionalização, seriam, sobretudo, "pontos de passagem obrigatórios", "frentes simultâneas" e não obedeceriam a uma ordem preestabelecida.

Por outro lado, enquanto Wilensky acompanha o desempenho de 18 profissões ao Iongo do tempo, amparado em dados estatísticos, e constrói um modelo abstrato e adaptável a toda e qualquer condição, Latour nos apresenta as suas "regras do método", penetrando de forma quase que antropológica no laboratório, desvendando sua rotina.

Neste aspecto, reside, no nosso entender, a singularidade mais instigante da perspectiva analítica proposta por Latour, uma vez que triIha um caminho distinto, inovador e interessante. Em vez de partir de 18 profissões diferentes e criar um modelo que tenha a intenção de dar conta de todas as diferenças constitutivas do processo de profissionalização, Latour acompanha alguns pesquisadores ao longo de seu dia-a-dia de trabalho no interior de um laboratório. Da parte, ele não pretende criar uma

\begin{tabular}{lll}
\hline Etapas - Autor & Wilensky & Latour \\
\hline Primeira & Eliminar amadores & Eliminar amadores \\
Segunda & Formação padronizada & Satisfazer a sociedade \\
Terceira & Associações profissionais & Provar ao Estado \\
Quarta & Provar ao Estado & Formação padronizada \\
Quinta & Normas éticas & Normas éticas \\
\hline
\end{tabular}


regra aplicável ao todo. Da parte, ele constrói uma maneira de olhar outras singularidades semelhantes (mas diferentes) àquela por ele observada.

À primeira vista, a obtenção de um diploma de nível superior seria um elemento suficiente para que a profissão de cientista recebesse atenção, dinheiro e confiança da sociedade. $\mathrm{O}$ que ele procura nos mostrar é que estes fatores são determinantes, mas não suficientes. Dois casos descritos por ele serão apresentados a seguir: o caso do geólogo e o de um chefe de laboratório. Ao reproduzir parte de sua narrativa, temos o intuito de desvendar e analisar o olhar inovador que Latour nos apresenta.

O caso do geólogo

Um dos investimentos de pesquisa implementados por Latour nesta obra relaciona-se com a análise que faz de um geólogo, na época em que não existiam nem a disciplina (Geologia), nem a profissão. Como um historiador, sofrendo forte influência da antropologia, Latour acompanhou o dia-a-dia do trabalho de um certo senhor chamado Lyell, que, em 1820, desejava estudar a "História da Terra". Em meados do século XIX, este tipo de investigação relacionava-se tanto com a Teologia, quanto com a Paleontologia, ou seja, não havia um campo de conhecimento definido voltado especificamente para os estudos da origem, formação e das sucessivas transformações do globo terrestre, como existe atualmente. As instituições, os parceiros e os aliados não estavam ainda constituídos.

Para Latour, não basta definir e dominar certa área do saber. Há que implementar simultaneamente movimentos persuasivos em duas direções: por um lado cabe conquistar a aceitação e o reconhecimento junto à comunidade científica e ao Estado. Por outro lado, deve-se convencer a sociedade sobre a necessidade da existência desta atividade. Para que obtenham êxito, estes dois movimentos devem promover alianças políticas e institucionais, fora do laboratório, que garantam sua própria sobrevivência.

No primeiro caso, por exemplo, Lyell deve “despertar o interesse não apenas da nobreza, como também das altas autoridades do Estado, convencendo certos organismos de que a Geologia traduz seus interesses, produzindo um grande número de fatos novos e inesperados, que poderiam ser considerados soluções para certos problemas" (Latour, 1989:242). No segundo caso, a profissão deve provar que o conhecimento que detém carrega altos índices de benefício social. Assim, o Estado passará a financiá-la e ela terá condições de competir com outras disciplinas, chegando a conquistar o monopólio tão desejado.

Seguindo a perspectiva proposta por Latour, na Geologia, assim como em outras áreas do conhecimento, há que se analisar de que maneira uma atividade conseguiu convencer as autoridades acadêmicas, o Estado e os clientes de sua utilidade, erguendo-se e sobrepujando-se contra as convicções até então aceitas, contrárias à sua existência. Da mesma forma há que se buscar compreender como certa profissão estabel ecida e reconhecida pelo Estado, pela sociedade e pela comunidade científica perdeu seu prestígio, poder econômico e político, tornando-se uma ocupação.

\section{O diretor de um laboratório}

A área da Saúde Pública não é muito diferente das demais. Enquanto alguns cientistas passam os dias investigando, lendo ou escrevendo, outros atuam, procurando levantar verbas suplementares para o mesmo projeto. Qual dos dois faz pesquisa?

Para descrever o processo de profissionalização do cientista, Latour acompanha o dia-adia de um diretor de laboratório de pesquisas, reproduzindo, ao mesmo tempo, as atividades que um grupo de pesquisadores desempenhou durante uma semana. Ele constata, assim, que este diretor ocupou todo o seu tempo implementando estratégias para recrutar investidores, interessar e convencer pessoas da relevância, originalidade e pertinência da pesquisa desenvolvida em seu laboratório. Enquanto isto, os pesquisadores dirigidos por ele passaram a mesma semana, 12 horas por dia, trancados em um laboratório.

Afinal de contas, ele se pergunta, quem são os que fazem realmente pesquisa? Onde se faz pesquisa de verdade?

Uma resposta possível seria acompanhar a lógica dos que acreditam numa real diferença entre o interior e o exterior da atividade em ciência e tecnologia. Há os que defendem que a pesquisa se faz exclusi vamente dentro do laboratório. Estes seriam os "internalistas" ou "difusionistas". Por outro lado, há os que entendem que a atividade do laboratório só sobrevive graças à mobilização política e financeira que se faz do lado de fora do laboratório. Estes seriam denominados "externalistas". Para eles, a atividade de "pesquisa pura" é sobredeterminada pela questão social e política. O divórcio entre essas duas perspectivas de investigação traduz-se no debate acadêmico entre internalistas 
e externalistas, muito presente ainda em alguns fóruns onde se discute a história das ciências e das técnicas. Para Latour, se você seguir um dos caminhos, contará uma história. Se escolher o outro, a história será completamente diferente.

Latour condena tanto os "internalistas" quanto os "externalistas". A crítica que faz aos internalistas relaciona-se ao fato de pretenderem analisar o processo de produção científica como sendo exclusivamente fruto do trabalho de pesquisadores, construindo uma imagem idílica, pura e desinteressada da atividade científica. Quando se fala de ciência, os leitores, convencidos por esta perspectiva, pensam logo em sábios célebres, em disciplinas e universidades com prestígio que produzem novas idéias e conhecimentos completamente dissociados do que se passa na sociedade. Acompanhando a maneira como o autor estrutura sua crítica aos internalistas, mais uma vez nos surpreendemos. Latour recorre às estatísticas oficiais e constata o reduzido número de profissionais inscritos no recenseamento federal, nos Estados Unidos, como "cientistas", assim como a quantidade, menor ainda, possuidora de um doutorado. Ele usa esses dados para desmontar a lógica internalista, que acredita que aqueles que trabalham no laboratório são os únicos que fazem realmente ciência: “Não é possível que esta minoria consiga, sozinha, recrutar os fundos necessários para produzir conhecimento e convencer toda a população de sua eficácia" (Latour, 1989:246). Os internalistas defendem, por outro lado, que os cientistas, apesar de serem tão poucos, fazem tanto e influenciam tanta gente porque são os melhores e os mais brilhantes, e que, por essa razão, as pessoas acreditam neles. Assim, Latour procura apresentar não apenas os próprios argumentos, mas também introduz aqueles sustentados pelos internalistas.

A crítica que faz aos externalistas vinculase ao fato de conceberem o trabalho científico como sendo fruto exclusivo das determinações sociais, políticas e econômicas que sofre durante sua elaboração. Os external istas, no seu entender, erram quando cuidadosamente negligenciam a análise dos conteúdos das disciplinas e a realidade dos laboratórios.

Para Latour, a qualidade da pesquisa que se desenvolve no interior do laboratório não é determinada apenas pela capacidade de articulação política do diretor, em seu exterior. A decisão do Ministro, por sua vez, não é influenciada exclusivamente pelo que se faz no laboratório. No seu entender, não existem duas histórias: uma das coisas e outra das pessoas. Só existe uma.
O autor retoma o exemplo do diretor que sai à busca de financiamento e reconhecimento, e o dos pesquisadores que permanecem no interior do laboratório. Para ele, um pesquisador só é capaz de permanecer exclusivamente dentro do laboratório porque outro está constantemente fora procurando novas fontes de recursos. No seu entender, há uma relação direta entre a intensidade do trabal ho exterior de recrutamento e a tensão sofrida no interior do laboratório. Muitas vezes, uma pesquisa só tem condições de se desenvolver se o ambiente onde a investigação está instalada for equipado adequadamente. Outras vezes uma pesquisa só consegue instalações adequadas se estiver desenvolvida o suficiente e apresentar argumentos convincentes às agências financiadoras.

Compõe-se, assim, um quadro de dupla pressão. Uma vem dos que permanecem no laboratório e volta-se sobre os que articulam com as fontes financiadoras e que estão no exterior. Se o financiamento não for obtido, o ambiente no laboratório torna-se tenso, pois o trabalho terá poucas condições de ter continuidade. A outra pressão origina-se dos que estão no exterior. As inovações científicas produzidas no interior de um laboratório devem estar cercadas de provas. Os que articulam colegas, revistas científicas de divulgação, autoridades e instituições não podem ter seus produtos passíveis de críticas ou contestações. Assim, os que permanecem do lado de fora exercem pressão sobre os que ficam no laboratório para que produzam dados confiáveis e comprováveis. Para Latour, as ciências têm um interior porque têm um exterior. Quanto mais importante, sólida e pura for a ciência produzida no interior, tanto mais os outros pesquisadores, agenciadores de prestígio e verbas, devem ir longe em direção ao exterior. Assim, o autor não vê condições de uma face existir se não estiver apoiada na outra. São dois trabalhos distintos. Um, entretanto, não sobrevive sem o outro.

Utilizando o método que denominou “lógica da tradução", Latour se propõe a contar uma única história, qualquer que seja o ponto de entrada. Se você seguir o pesquisador na bancada, chegará ao diretor do laboratório que negocia financiamento. Se você acompanhar o dia-a-dia do diretor, chegará ao laboratório, sua bancada, microscópios, lentes e todos os utensílios necessários. Para ele, a capacidade de trabalhar num laboratório depende do sucesso obtido por outros pesquisadores na coleta de recursos e vice e versa.

Aprofundando sua argumentação, Latour considera que os pesquisadores que permanecem no laboratório representam a ponta de um 
iceberg. No seu entender, é necessário muito mais gente no exterior para tornar possível o trabalho daqueles que acham que fazem "ciência pura". Seguindo a "lógica da tradução", proposta pelo autor, podemos concluir que os que contribuem para a definição, a difusão, a divulgação, o convencimento da utilidade, a negociação, a gestão, a regulamentação, a inspeção, o ensino, a venda e a manutenção dos produtos gerados no laboratório, apesar de não permanecerem no interior deste, são parte integrante da pesquisa.

Assumindo esta perspectiva, surge um problema metodológico. Como fazer este tipo de análise, já que, por definição, as estatísticas sobre força de trabalho só denominam cientistas as pessoas oficialmente engajadas na ciência e que desenvolvem sua atividade em laboratórios ou centros de pesquisa? Para Latour, a análise dos orçamentos, mesmo se estiverem deformados pelas estatísticas, é um dos caminhos possíveis para resolver esta questão. Eles representam, de maneira geral, um bom termômetro para que se avalie até que ponto os pesquisadores foram capazes de suscitar interesse das autoridades e das agências financiadoras com seu trabalho. Para conseguir o montante de verba firmado nos orçamentos, o pesquisador não pode ficar fechado em seu laboratório. Em sua equipe, uma parte fará o trabaIho de persuasão e negociação com o Estado, as agências financiadoras e a sociedade em geral, enquanto outra se manterá próximo ou dentro do laboratório.

\section{Considerações finais}

Como alguém se torna cientista?

Esta foi a pergunta que abriu este artigo. Entendemos que nosso intuito foi cumprido, ou seja, na análise que fizemos, a visão de Latour foi suficiente para desmistificar a resposta que se tem comumente para esta pergunta. Para boa parte da opinião pública, um cientista é alguém que se dedica integral e exclusivamente a seu trabalho de pesquisa e, além disso, domina um conhecimento sofisticado e incompreensível por leigos. A concepção de Wilensky sobre o processo de profissionalização coincide, a nosso ver, com aquela presente no senso comum. Para Wilensky, uma ocupação pode se tornar uma profissão se dominar um conhecimento esotérico, complexo, institucionalizado e aplicável. Para ele, como para a opinião pública em geral, esta condição é determinante e imprescindível para a caracterização de uma profissão, sobretudo a de cientista.
Para Latour, o domínio e a delimitação do conhecimento é fundamental ao processo de profissionalização, sem ser, entretanto, determinante ou imprescindível.

Para apresentar sua visão, Latour percorre um caminho ao mesmo tempo sinuoso e instigante. Tanto no caso do geólogo Lyell, quanto no do diretor de um laboratório, o autor implementou uma descrição etnográfica, que confirmou sua hipótese principal. Latour acredita que, para que sejam analisadas as razões do sucesso de uma atividade que se profissionaliza, deve-se trabalhar simultaneamente com duas dimensões: o lado de dentro e o de fora do processo de produção do conhecimento propriamente dito. Ele admite que poderia adotar e reproduzir a lógica dos que acreditam numa real diferença entre estes dois lados, ou mesmo dos que entendem que exista uma determinação de um lado sobre o outro. Para ele, “embora esta lógica seja aceita pela maioria dos analistas, ela nos é absolutamente proibida" (Latour, 1989:258). Segundo Latour, nenhum fator deve ser privilegiado quando um processo de profissionalização for analisado. Uma investigação sobre o trabalho científico deve recompor todos os seus meandros, duvidando tanto das ciências sociais quanto das ciências ditas sólidas. Não se trata de decidir que fatos pertencem ao social e quais ao científico. Ao contrário, Latour postula que os dois caminhos sejam seguidos simultaneamente. $\mathrm{O}$ próprio autor, entretanto, chega a duvidar do sucesso de seu empreendimento. “Teríamos nós percorrido todo esse caminho e conseguido escapar à frigideira da ciência somente para cair no fogo da sociedade? Sairemos algum dia dos descaminhos do internalismo para recair a cada vez nas aberrações do externalismo? Seremos obrigados a escolher um meio termo entre internalismo e externalismo, meio termo este que cumularia os absurdos?" (Latour, 1989:285).

Apesar destes argumentos, expostos pelo próprio Latour, acreditamos que tenha conseguido sair tanto das frigideiras e descaminhos do internalismo quanto do fogo e das aberrações do externalismo. Concordamos, assim, com Hochmam (1994), quando afirma que a proposta metodológica de Latour é uma reação "tanto às análises que atribuem um lugar especial ao conhecimento científico (...) quanto aos críticos desta postura que (...) acabam por não atentar para a prática da pesquisa como ela é produzida atualmente" (Hochman, 1994:214). Um dos grandes méritos da abordagem de Latour foi o de ter conseguido apresentar uma visão do processo de profissionalização que, ao 
mesmo tempo, não dá ênfase nem ao domínio do conhecimento, como fazem os internalistas, nem privilegia a soberania do social, como querem os externalistas. Cabe mencionar que, apesar de aparentemente resolvida, esta oposição - visão internalista X visão externalista permanece extremamente viva. Superar esta oposição artificial representa um dos grandese instigantes desafios para aqueles que pretendam fazer história das ciências e de sua profissionalização, nos vários ramos do conhecimento.

Como alguém se torna cientista?

Recorremos à mesma pergunta para fazermos outra. Qual foi o método utilizado pelos autores que foram objeto de nossa análise?

Ao longo deste texto, acreditamos ter sido possível compreender suas divergências e convergências no plano teórico e conceitual com base nas respectivas construções e operações concretas adotadas. Metodologicamente, Latour penetra no laboratório procurando resgatar seu dia-a-dia, seus conflitos e interesses distintos. Wilensky, por seu lado, parte da constatação das etapas comuns 18 profissões nos Estados Unidos e, com isso, cria um esquema teórico abrangente, aplicável, no seu entender, a todas as atividades do mundo do trabalho.

Tivemos o cuidado de ressaltar que cada um destes autores produziram trabalhos em momentos históricos distintos, tendo sido, portanto, informados por preocupações e escolas de pensamento bastante diferenciadas. Este ponto de partida não desqualificou, a nosso ver, o empreendimento que nos dispomos a enfrentar. Muito pelo contrário, a contraposição apresentada teve o mérito de aguçar a perspectiva crítica, imprescindível para trabaIhos desta natureza.

A historicidade do processo de profissionalização não foi, para nós, objeto de interesse de nenhum dos dois autores. Nem poderia ter sido diferente. Esta não era a preocupação de nenhum deles. Latour procurou diluir a oposição existente entre internalistas e external istas, enquanto Wilensky buscou estabelecer um tipo ideal de "ser profissional". Duas iniciativas louváveis e que contribuíram enormemente para a caracterização do que venha a ser uma profissão em termos sociológicos. Ambas abordagens integram atualmente a história da construção deste conceito.

Mas, o que seria introduzir a dimensão histórica às análises sobre processos de profissionalização?

Recentemente, autores como Starr (1982) e Herzlich (1995) buscaram associar as histórias de seus países com a história da profissão mé- dica em cada realidade específica. Lendo e analisando estas duas obras, tivemos condições de perceber que "o lugar da ciência na configuração da profissão foi, para ambos os autores, tido como secundário ou pouco significante. (...) Os autores combinaram, em suas análises, uma face sócio-histórica com outra voltada para o próprio desenvolvimento científico do conhecimento médico e suas repercussões sociais"(Pereira, 1995a:24).

Starr (1982) e Hezlich (1995) concluíram que a análise histórica e sociológica da profissão não pode ser vista dissociada da sociedade e do movimento científico que nela se inscreve (Pereira, 1994). A necessidade da associação destas dimensões tem sido uma de nossas preocupações em produções recentes. No nosso entender, a dimensão histórica deve ser introduzida na análise das profissões em função, pelo menos, de duas coordenadas que consideramos fundamentais: "Por um lado cabe fazer uma referência à história social em que esta profissão está inserida e da qual faz parte. Por outro lado cabe reconhecer a historicidade do processo profissional" (Pereira, 1995b:612).

Este esforço de definição conceitual e de associação destas várias dimensões, na área das ciências sociais, acabou de ser revitalizado com o lançamento da coletânea organizada por Machado (1995a). Nela, os diversos autores, inseridos na área da sociologia das profissões, buscam estabelecer uma "conexão entre a base cognitiva, o mercado de trabalho, os aspectos do ambiente (Estado, sociedade, associações civis, instituições etc.), os avanços tecnológicos - seus efeitos no mundo profissional, a dimensão das arenas conflitivas e de competição entre elas e no interior delas" (Machado, 1995b:11).

Esta postura instigante e criativa de tratar o fenômeno profissional tem integrado a agenda de alguns estudos de cunho sociológico e histórico que fizeram da profissão seu objeto preferencial de análise (Schraiber, 1993). Ao realizarmos o empreendimento que este artigo busca traduzir, não tivemos a intenção de esgotar as possibilidades interpretativas que Latour eWilensky portam. Nosso objetivo foi o de contribuir para o debate acadêmico sobre a legitimidade da utilização do conceito profissão enquanto objeto de estudo sociológico e histórico (Barbosa, 1993), bem como discutir algumas novas perspectivas metodológicas que o objeto tem suscitado. 


\section{Agradecimentos}

Agradeço à professora Dra. Vera Portocarrero (Casa de Oswaldo Cruz/ Fiocruz e Uerj), pelos comentários e sugestões durante a elaboração deste texto. Os erros e omissões que ele contém são, entretanto, de minha inteira responsabilidade.

\section{Referências}

BARBOSA, M. L., 1993. A sociologia das profissões: em torno da legitimidade de um objeto. Bol etim Bibliográfico de Ciências Sociais, 36:3-30.

DURKHEIM, E., 1984. A Divisão do Trabalho Social. Porto: Editorial Presença.

HERZLICH, C., 1995. A evolução das relações entre médicos franceses e o Estado, de 1880 a 1980. In: Profissões de Saúde: Uma abordagem Sociológica (M. H. Machado, org.), pp. 75-89, Rio de Janeiro: Editora Fiocruz

HOCHM AN, G., 1994. A ciência entre a comunidade e o mercado: leituras de Kuhn, Bourdieu, Latour e Knorr-Cetina. In: Filosofia, História e Sociologia das Ciências. Abordagens Contemporâneas (V. Portocarrero, org.) pp. 199-232. Rio de Janeiro: Editora Fiocruz.

LATOUR, B., 1989. Les professions. In: La Science en Action (B. Latour, org.) pp. 236-286. Paris: Éditions La Découverte.

MACHADO, M. H., 1991. Sociología de las profesiones: un nuevo enfoque. Educación Médica y Salud, 25:28-36.

MACHADO, M. H., 1995a. Profissões de Saúde: Uma Abordagem Sociológica. Rio de Janeiro: Editora Fiocruz.

MACHADO, M. H., 1995b. Sociologia das profissões: uma contribuição ao debate teórico. In: Profissões de Saúde: Uma Abordagem Sociológica.( M. H. Machado, org.) pp. 13-33. Rio de Janeiro: Editora Fiocruz.

MARINHO, M. J., 1986. Profissionalização e Credenciamento: A Política das Profissões. Rio de Janeiro: Senai.

PEREIRA, A., 1994. A história da profissão médica nos Estados Unidos: o ponto de vista de Paul Starr. Estudos em SaúdeColetiva, 101:23.

PEREIRA, A., 1995a. A história da profissão médica: algumas considerações metodológicas. Estudos em Saúde Coletiva, 122:28.

PEREIRA, A., 1995b. A profissão médica em questão (1922): dimensão histórica e sociológica. Cadernos de Saúde Pública, 11:600-615.

SCHRAIBER, L. B., 1993. O Médico e seu Trabalho. Limites da Liberdade. São Paulo: Hucitec.

STARR, P., 1982. The Social Transformations of American Medicine. New York: Basic Books

WEBER, M., 1982. A Ciência como Vocação. Ensaios de Sociologia. Rio de Janeiro: Guanabara.

WILENSKY, H. L., 1970. The professionalization of everyone? In: The Sociology of Organizations: Basic Studies (O. Grusky \& G. Miller, eds.), pp. 483501, New York: The Free Press. 